\title{
The Design of the Peanut Sheller Transmission Device
}

\author{
Yuan Ren, Yongchang Yu, Binbin Zhao and $\mathrm{He} \mathrm{Li}^{*}$ \\ Henan Agriculture University, Zhengzhou, China \\ *Corresponding author
}

\begin{abstract}
In order to improve peanut sheller's shelling and cleaning efficiency, this thesis chooses the scraper shelling device on the basis of studying other peanut shellers. And it also determines the overall scheme design of sheller and introduces the scraper structure and working principle of the peanut sheller. It puts its focus on the peanut sheller's transmission structure design, which includes the choice of actuator components, $V$ belt, $V$ belt wheel design, design of the main shaft and parameters calculation, bearing and the choice of key. Through the optimization of gear design, the work efficiency and stability of the peanut sheller are improved further.
\end{abstract}

Keywords-peanut sheller; scraper shell; parameter calculation; transmission structure

\section{INTRODUCTION}

Peanuts are rich in large amounts of fat and protein. They are not only one of the most important sources of vegetable oil in our daily life, but also an important source of our daily intake of vegetable protein. Peanut sheller is a kind of machine by using the methods of extrusion, shearing to remove the shell so as to get a peanut. And at present time the key components of peanut sheller in our country still stays in the previous level, caused by a lack of money. There are many problems about peanut sheller such as low rate, serious breakage, unstable performance, poor adaptability and high shelling cost [1]. In order to solve these problems, this thesis designs the scraper peanut sheller transmission device to improve the utilization rate of its stability and generality through the improvement of the technical scheme of the peanut sheller.

\section{STRUCTURE AND WORKING PRINCIPLE OF THE SCRAPER TYPE PEANUT SHELLING MACHINE}

Scraper type peanut shelling machine mainly consists of inlet tank shelling shaft parts (including the scraper frame, and a scraper) inertial vibrating screen, fan, a motor, a bracket, a peanut shell collecting bucket and other components.

As shown in figure I .Running process is from the top to down. Start from the collection of peanuts, peanut shelling into the box. After the scraper extrusion and the impact can be made after the shelling, some are not in the peanut shelling grid above again after rolling and extrusion of shelling scraper. The scraper and grid gap called the shelling gap, shelling gap influence crushing rate and productivity. The half cage grid bar and the grid strip gap influence the breaking rate and the net rate of the net. The bar is made into a semi cage sieve is fixed on the box shell, after shelling of peanut shell and peanut kernels after half cage sieve whereabouts, also by the fan and the wind blowing, the peanut shell into the collecting bucket. Peanut and peanut kernels because of the relatively heavy fall to the inertia of the screen, the inertia sieve to separate the peanuts and peanut. Under the action of inertia screen, the peanut kernel is collected from the filter. Peanut collected at a distance in a little bit small half cage sieve for shell.

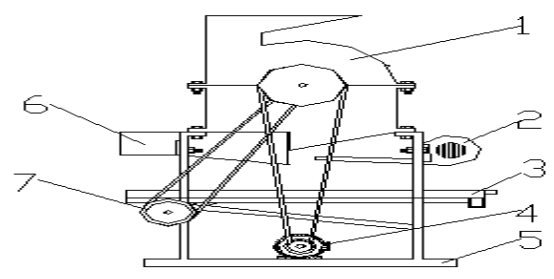

1. Shell Box 2.Fan 3.Peanut Export 4.Electric Machinery 5.Frame 6.Peanut Shell Collection Box 7.Transmission

FIGURE I. THE MAIN STRUCTURE OF THE SCRAPER TYPE HULLING MACHINE

\section{SELECTION OF DRIVE COMPONENTS}

\section{A. Selection of Available Drive Components}

Transmission mode can choose a gear drive or $\mathrm{V}$ belt drive. Generally speaking, with lower cost of transmission, for scraper type peanut shelling machine this kind of transmission ratio is not very high machine can choose to use belt drive to achieve the effect of deceleration, belt transmission also has the advantages of stable transmission, low noise and manufacturing more convenient features[2].

\section{B. Motor Selection}

Motor options include type, power, and speed, and the model is determined finally. According to the calculation of the power and speed of the shaft, two motor models can be determined: Y100L-6 and Y90L-4[3]. According to the speed and the speed of the scraper, the total transmission ratio can be calculated .And the ratio of the two motor drives can be obtained from the table I.

From te table we can see that in the program 1 the total transmission ratio is small, but the price is high, and it does not apply to the family of small agricultural machinery, so the better choice is program 2: motor model Y90L-4, center 
distance of $\mathrm{H}=90 \mathrm{~mm}$, shaft diameter $24 \mathrm{~mm}$, shaft overhang length $50 \mathrm{~mm}$, total width $180 \mathrm{~mm}$.

Shaft speed ${ }^{[2]}: \mathrm{n}_{1}=1400 \mathrm{r} / \mathrm{min}$

$$
\begin{aligned}
& n_{2}=n_{1} / i=367.5 r / \min \\
& n_{1} / n_{2}=1400 / 367.5=3.81
\end{aligned}
$$

Shaft input power:

$$
P_{2}=P_{d} \times \eta_{2}^{2}=1.5 \times 0.95^{2}=1.35 \mathrm{kw}
$$

Shaft torque: $\mathrm{T}_{2}=9550 \mathrm{P}_{2} / \mathrm{n}_{2}$

$$
T_{2}=9550 \times \frac{1.35}{367.5}=35.081 \mathrm{~N} \cdot \mathrm{m}
$$

\section{TABLE I. TRANSMISSION RATIO}

\begin{tabular}{llccll}
\hline $\begin{array}{l}\text { Scheme } \\
\text { Number }\end{array}$ & $\begin{array}{c}\text { Motor } \\
\text { type }\end{array}$ & $\begin{array}{c}\text { Rated } \\
\text { power }\end{array}$ & $\begin{array}{l}\text { Synchronous } \\
\text { speed }\end{array}$ & $\begin{array}{l}\text { Full load } \\
\text { speed }\end{array}$ & $\begin{array}{l}\text { Total transmission } \\
\text { ratio }\end{array}$ \\
\hline 1 & Y100L-6 & $1.5 \mathrm{kw}$ & $1000 \mathrm{r} / \mathrm{min}$ & $940 \mathrm{r} / \mathrm{min}$ & $2.459 \mathrm{i}$ \\
2 & Y90L-4 & $1.5 \mathrm{kw}$ & $1500 \mathrm{r} / \mathrm{min}$ & $1400 \mathrm{r} / \mathrm{min}$ & $3.81 \mathrm{i}$ \\
\hline
\end{tabular}

\section{V BELT DRIVE DESIGN BETWEEN MOTOR AND SHAFT}

\section{A. V-belt Calculation}

The mechanical motor type had been determined from the choice of the motor and some relevant values of the calculation, and we know that the rated power of $1.5 \mathrm{KW}$ (by the design of the separation device); synchronous speed of $1500 \mathrm{r} / \mathrm{min}$; full speed of $1400 \mathrm{r} / \mathrm{min}$; transmission ratio $=3.81[4]$. From this, it can be obtained by using the calculation formula of the manual:

1) Determine the calculation power $P_{c a}$

$$
P_{c a}=K A P=1.1 \times 1.5=1.65 \mathrm{kw}
$$

\section{2) Model selection of $V$-belt wheel}

$\mathrm{V}$-belt includes ordinary $\mathrm{V}$ belt and narrow $\mathrm{V}$ belt, which are already standardized. The ordinary $\mathrm{V}$ belt contains 7 different models: Z, A, B, C, Y, D, E. The other narrow V contains 4: SPA, SPB, SPZ, SPC. According to the ${ }^{N_{1}}, P_{c}$, we can find the most suitable belt is A from the mechanical design manual.

3) Determine the diameter of the belt wheel

In order to reduce the bending stress at work, it should be used to focus too much on the large belt wheel diameter, so that the main belt wheel and the size of the belt wheel are too large. According to the driving wheel reference diameter lines selected pulley diameter $\mathrm{d}_{\mathrm{d} 1}=75 \mathrm{~mm}$, and the reference wheel diameter can also be calculated: $d_{d 1}=75 \mathrm{~mm}$

Diameter of the driven wheel:

$$
d_{d 2}=i_{1} \times d_{d 1}=3.81 \times 75 \mathrm{~mm}=286 \mathrm{~mm}
$$

From the power formula $\mathrm{P}=\mathrm{FV} / 1000$ we can know that when the power $\mathrm{P}$ reaches to a certain value, the speed of the $\mathrm{V}$ will be higher. According to the formula we can see that the circumference of the required $\mathrm{F}$ is small, so the number of $\mathrm{V}$ belt will not need so much [5].

$$
v=\frac{\pi d_{d 1} n_{1}}{60 \times 1000}=\frac{\pi \times 75 \times 1400}{60 \times 1000} \mathrm{~m} / \mathrm{s}=5.498 \mathrm{~m} / \mathrm{s}
$$

$5 \mathrm{~m} / \mathrm{s}<v=5.498 \mathrm{~m} / \mathrm{s}<25 \mathrm{~m} / \mathrm{s}$

From above we can see the design is suitable.

4) Determine the base length and the center distance a:

The center distance $a_{0}=700 \mathrm{~mm}$ is in line with $0.7\left(d_{1}+d_{2}\right)<a_{0}<2\left(d_{1}+d_{2}\right)$

The reference length of the relevant literature is $L_{d}=2240 m$ [2]. Calculate the actual center distance a:

$$
a=a_{0}+\frac{L_{d}^{\prime}-L_{d}}{2}=(700+111) \mathrm{mm}=811 \mathrm{~mm}
$$

5) Checking the package angle on the active wheel ${ }^{\alpha_{1}}$ : $\alpha_{1}=180^{\circ}-\left(d_{2}-d_{1}\right) / a \times 57.3^{\circ}=160.07^{\circ}>120^{\circ}$

6) Calculate the number of $V$ bands $\mathrm{z}$ :

$$
z=\frac{P_{c a}}{\left(P_{0}+\Delta P_{0}\right) k_{\alpha} k_{l}}
$$

Known $n_{1}=1400 \mathrm{r} / \mathrm{min}, d_{d 1}=75 \mathrm{~mm}, \quad i=3.81$, Checklist: $P_{0}=0.68 \mathrm{kw}, \Delta P_{0}=0.17 \mathrm{kw}, K_{\alpha}=0.95, K_{l}=1.01$. These values are substituted into the formula, the calculation of $\mathrm{Z}=1.99$, so the root number is 2 .

7) Calculating the pressure on the wheel axle ${ }^{F_{q}}$ : Check list $q=1.1 \mathrm{~kg} / \mathrm{m}$

$$
F q=500 \frac{P_{c a}}{v z}\left(\frac{2.5}{K_{\alpha}}-1\right)+q v^{2}=114.75 \mathrm{~N}
$$

8) Calculation of effect of axial force on the shaft ${ }_{\mathrm{Q}}$ :

$$
F_{\mathrm{Q}}=2 \mathrm{zF}_{0} \sin \frac{\alpha_{1}}{2}
$$

By numerical calculation, ${ }_{Q}{ }_{Q}=678.04 \mathrm{~N}$

\section{B. V-belt Pulley Design}

1) The material of the $V$-belt wheel

We can choose HT150 as the material of belt wheel, because the load of the scraper type peanut shelling machine is smaller.

\section{2) Structure of the belt pulley}

According to the different structural dimensions of the used belt wheel, the V-belt wheel is usually used in the form of solid, orifice plate, web type and oval shape. The small pulley $\mathrm{d} 1<2.5 \mathrm{~d}$, so we can use the solid type because of its small size. And the large pulley diameter $\mathrm{d}_{2}<400 \mathrm{~mm}$, it can be used in the form of a pulley to reduce its weight.

\section{3) Wheel groove design of $V$-belt}

$\mathrm{V}$-belt pulley groove size is based on the $\mathrm{V}$ belt of the corresponding type [6]. The size of the pulley and the pulley with the type of the corresponding size is shown in Table II . 
TABLE II. WHELL GROOVE SIZE

\begin{tabular}{|c|c|c|}
\hline Size type & Small pulley & Large belt wheel \\
\hline Wheel groove type & A & $\bar{A}$ \\
\hline Reference diameter & $75 \mathrm{~mm}$ & $286 \mathrm{~mm}$ \\
\hline Base width $b_{d}$ & $11.0 \mathrm{~mm}$ & $11.0 \mathrm{~mm}$ \\
\hline Base line groove depth ha & $2.75 \mathrm{~mm}$ & $2.75 \mathrm{~mm}$ \\
\hline $\begin{array}{l}\text { Base line groove depth } \\
h_{\text {fmin }} \\
\text { Slot spacing e }\end{array}$ & $15 \pm 0.3 \mathrm{~mm}$ & $15 \pm 0.3 \mathrm{~mm}$ \\
\hline $\begin{array}{l}\text { The first groove } \\
\text { symmetry plane to the } \\
\text { end face distance } \\
\text { Flange thickness } \delta\end{array}$ & $\begin{array}{c}10_{-1}^{+2} \mathrm{~mm} \\
12 \mathrm{~mm}\end{array}$ & $\begin{array}{l}10_{-1}^{+2} \mathrm{~mm} \\
12 \mathrm{~mm}\end{array}$ \\
\hline
\end{tabular}

4) Technical requirements for the $V$ belt pulley

$\mathrm{V}$ belt wheel of the casting (round, web, a spoke and hub) does not allow air bubbles, shrink pores, cracks and voids. We can add some convex platform, web parts in the casting process to repair the surface defective parts when the stress does not improve under the premise.

\section{Design and Parameter Calculation of Spindle}

The main part in design of peanut shelling machine is the axial design. The axis is used to support scraper, and rotate mechanical parts and have a torque transfer function. Mechanical requirements and manufacturing process should be considered in the design of the shaft. Choosing the appropriate material, the shape of the axis of the various parts of the design is also needed [3]. From above we can conclude the main shaft of the main parameters: speed $\mathrm{n}=367.5 \mathrm{r} / \mathrm{min}$, the input power of $\mathrm{P}_{2}=1.35 \mathrm{kw}$, and torque is $35.08 \mathrm{~N} \cdot \mathrm{m}$

\section{1) Choose the material of the main shaft}

Material of carbon steel and alloy steel are usually used on the multi shaft. Since this shaft has no other special requirements, we can choose the modulation process of 45 steel according to mechanical design manual.

2) Estimation of minimum shaft diameter Take $A_{0}=105$, then get:

$$
d_{\min }=A_{0} \sqrt[3]{\frac{P_{2}}{n_{2}}}=105 \sqrt[3]{\frac{1.35}{367.5}}=16.2 \mathrm{~mm}
$$

\section{3) Structure design of main shaft}

The design includes the design of the structure of the output shaft and the design of all dimensions [7]. The design of the shaft starts with the installation of the V pulley, and the $d_{1}=22$. To meet the need for a fixed pulley mounted pulley end of the shaft, the diameter herein may choose $\mathrm{d}_{2}=28 \mathrm{~mm}$, and V pulley sizes of 50. Taking into account the ring with a V-belt with the shaft instead of matching shaft end coordinate, it can be taken to reduce the size so the first segment length $\mathrm{L}_{1}=49 \mathrm{~mm}$. The second section is to pass the bearing cover, and the total length of the bearing cover is $25 \mathrm{~mm}$. the distance between the ends of the sealing cover and the $\mathrm{V}$ belt is $32.5 \mathrm{~mm}$, so $\mathrm{L}_{2}=57.5 \mathrm{~mm}$. Install bearing at the third stage and according to the size required choose deep groove ball bearings 6207 , so they chose $\mathrm{d}_{3}=35 \mathrm{~mm}, \mathrm{~L}_{3}=17 \mathrm{~mm}$. Bearings and blade axial positioning should be arranged at the 4th stage ,and consider the blade and the wall thickness of the distance, so $d_{4}=60 \mathrm{~mm}, L_{4}=28$. Install actuator blade in spindle at the 5th, and scraper diameter $\mathrm{d}_{5}=60 \mathrm{~mm}$, mounting length of scraper frame $\mathrm{L}_{5}=500 \mathrm{~mm}$. Because the two ends of the shaft must be the same, and must meet the positioning of the bearing needs, so the sixth section of thed ${ }_{6}=35 \mathrm{~mm}, \mathrm{~L}_{6}=30 \mathrm{~mm}$. As shown in Figure II and Table III.



FIGURE II. SPINDLE DIAGRAM

TABLE III. THE SIZE OF THE SPINDLE PARAGRAPHS DESIGN

\begin{tabular}{lll}
\hline Shaft end & Diameter & Length \\
\hline Axis I & $22 \mathrm{~mm}$ & $34 \mathrm{~mm}$ \\
Axis II & $28 \mathrm{~mm}$ & $57.5 \mathrm{~mm}$ \\
Axis III & $35 \mathrm{~mm}$ & $27 \mathrm{~mm}$ \\
Axis IV & $65 \mathrm{~mm}$ & $18 \mathrm{~mm}$ \\
Axis V & $60 \mathrm{~mm}$ & $500 \mathrm{~mm}$ \\
Axis VI & $35 \mathrm{~mm}$ & $30 \mathrm{~mm}$ \\
\hline
\end{tabular}

4) Check of the shaft strength

From the calculation of the structure and the moment, we know that the fifth section of the shaft is a dangerous section [5]. Load analysis is shown in Figure 3. Stress calculation:

Torque: $\mathrm{T}=35.081 \mathrm{~N} \cdot \mathrm{mm}$. Diameter: $\mathrm{d}=60 \mathrm{~mm}$. Circumferential force $F_{\mathrm{t}}$

$$
F_{t}=2 T / d=35.081 \times 2 / 0.06=1169.37 N
$$

Radial force $F_{r}$ :

$$
F_{\mathrm{r}}=F \mathrm{t} \times \tan \alpha / \cos \beta=1415.2 N
$$

Axial force $F_{\alpha}$

$$
F_{\alpha}=F \mathrm{t} \times \tan \beta=634.4 \mathrm{~N}
$$

Known $A B=271.50 \mathrm{~mm}, B C=286.50 \mathrm{~mm}, C D=115.00 \mathrm{~mm}$. Supporti ng force on horizontal plane:

$$
\begin{aligned}
& R_{H 1}=F \mathrm{t} \times L_{B C} / L_{A C}=2367.7 \times 286.5 / 558=1215.7 N \\
& R_{H 2}=F \mathrm{t} \times L_{A B} / L_{A C}=2367.7 \times 271.5 / 558=1152.0 \mathrm{~N} \\
& \quad \text { Vertical support reaction: }
\end{aligned}
$$

$R_{V 1}=\left(F \mathrm{r} \times L_{B C}+F \alpha \times \mathrm{d} / 2\right) / L_{A C}=(1415.2 \times 286.5+634.4 \times 60 / 2) / 558=760.7 \mathrm{~N}$ $R_{V 2}=\left(F \mathrm{r} \times L_{A B}-F \alpha \times \mathrm{d} / 2\right) / L_{A C}=(1415.2 \times 271.5-634.4 \times 60 / 2) / 558=654.4 \mathrm{~N}$

Bending moment on the horizontal plane:

$M_{H}=660.0 N . \mathrm{m}$

Bending moment in vertical plane:

$M_{V}=394.0 N . \mathrm{m}$

Total bending moment:

$M=\sqrt{{M_{H}{ }^{2}+M_{V}{ }^{2}}^{2}}=\sqrt{660^{2}+394^{2}}=768.7 N \cdot \mathrm{m}$

Torque:

$\alpha_{T}=0.6 \times 71.03=42.618 N . \mathrm{mm}$ 
Calculate equivalent moment:

$$
M e=\sqrt{M^{2}+(\alpha T)^{2}}=\sqrt{768.7^{2}+0.042618^{2}}=768.7 N . \mathrm{m}
$$

Check the shaft strength. By formula:

$$
\sigma_{\varepsilon}=M \mathrm{e} / \mathrm{W}=768.7 \times 10^{3} /\left(0.1 \times 60^{3}\right)=35.59 \mathrm{Mpa}<\left[\sigma_{-1 \mathrm{~b}}\right]=75 \mathrm{Mpa}
$$

The result meets the requirements.
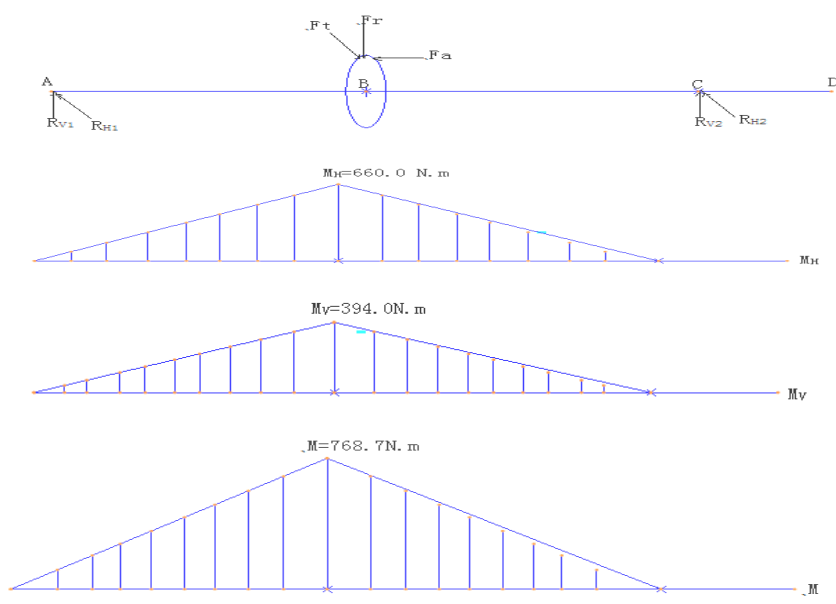

FIGURE III. LOAD ANALYSIS

\section{Selection of Bearings and Keys}

\section{1) Bearing selection}

The main function of the main shaft of the bearing is to support the shaft and shaft parts. Usually bearing were used to keep the rotation of the shaft rotation precision and reduce the friction between the shaft and support and wear. Rolling bearings because of low friction coefficient, less resistance, generally used in the accuracy of the machine is not too high. The choice of bearing depends on the shaft diameter of the shaft and the bearing [8]. And the bearing can bear the load and the load direction. While considering the axial positioning method and stiffness, rotational speed and the work environment requirements. Of course, here only the spindle bearings bear radial force, so it can be directly used to deep groove ball bearing [9]. Here we choose to use 6207 bearings. Bearing specific parameters are shown in Table IV.

\begin{tabular}{|c|c|c|c|c|c|c|c|c|c|c|c|}
\hline \multirow{3}{*}{6207} & \multicolumn{4}{|c|}{ Basic dimensions } & \multicolumn{3}{|c|}{$\begin{array}{l}\text { Installation } \\
\text { dimensions }\end{array}$} & \multicolumn{2}{|c|}{ Limiting speed } & Basic dynamic load & \multirow[t]{2}{*}{$\begin{array}{l}\text { Basic static } \\
\quad \text { load }\end{array}$} \\
\hline & d & $\mathrm{D}$ & B & $\mathrm{r}_{\mathrm{amin}}$ & $\underset{\min }{\mathrm{d}_{\mathrm{a}}}$ & $\begin{array}{l}\mathrm{D}_{\mathrm{a}} \\
\max \end{array}$ & $\begin{array}{c}\mathrm{r}_{\mathrm{a}} \\
\max \end{array}$ & Grease lubrication & Oil lubrication & $\mathrm{K}$ & \\
\hline & $\begin{array}{c}35 \\
\mathrm{~mm}\end{array}$ & $\begin{array}{c}72 \\
\mathrm{~mm}\end{array}$ & $\begin{array}{c}17 \\
\mathrm{~mm}\end{array}$ & $\begin{array}{c}1.1 \\
\mathrm{~mm}\end{array}$ & $\begin{array}{c}42 \\
\mathrm{~mm}\end{array}$ & $\begin{array}{c}65 \\
\mathrm{~mm}\end{array}$ & $\begin{array}{c}1 \\
\mathrm{~mm}\end{array}$ & $\begin{array}{l}8500 \\
\mathrm{r} / \mathrm{min}\end{array}$ & $\begin{array}{l}11000 \\
\mathrm{r} / \mathrm{min}\end{array}$ & $\begin{array}{r}25.5 \\
\mathrm{Cr}\end{array}$ & $\begin{array}{l}15.2 \\
\mathrm{C}_{0} \mathrm{r}\end{array}$ \\
\hline
\end{tabular}

TABLE IV. BEARING PARAMETERS

Bearing radial force:

$$
\begin{aligned}
& F_{r 1}=\sqrt{{R_{H 1}}^{2}+R_{V 1}{ }^{2}}=\sqrt{1215.7^{2}+760.7^{2}}=1434.08 \\
& \text { Fr } 2=\sqrt{{R_{H 2}{ }^{2}+R_{V 2}{ }^{2}}^{2}}=\sqrt{1152.0^{2}+654.4^{2}}=1324.89
\end{aligned}
$$

Because Fr1 $>$ Fr2, so as long as the bearing on the left side of the check. Access to information, $f_{p}=1.0 \sim 1.2$, Take intermediate value $f_{p}=1.1$

Equivalent load:

$p=f_{p} \times F_{r 2}=1.1 \times 1434.08 \mathrm{~N}$

Bearing life expectancy:

$L_{h}=10 \times 360 \times 8=28800 h$

Bearing life calculation:

$$
L_{h}=106 / 60 n \times\left(C_{r} / p\right)^{3}=106 /(60 \times 183.73) \times(25.5 / 1.43408)=5
$$
$09998 \mathrm{~h}>28800$

From the above calculation can be seen 6027 deep groove ball bearings can meet the requirements.

\section{2) Key selection}

The function of the key is to transfer the torque between the shaft and the shaft ${ }^{[9]}$. Here we use flat key to transfer the torque of the pulley to the shaft. The working surface of the flat key is on the two sides, and there is a gap between the upper surface of the key and the lower surface of the hub groove. Since the diameter of the shaft in front of us is $d_{1}=22 \mathrm{~mm}$, Reference 1096-2003 GB/T.

\section{CONCLUSION}

Facing a series of problems which our country existing peanut sheller, this topic from a practical point of view, on the basis of previous research design the scraper type peanut shelling machine. At the same time to determine the overall 
design of scraper type peanut shelling machine, design and calculation of various parts. Mainly introduces the detailed design of peanut shelling machine drive structure, including belt wheel, spindle, motor and other specific design and calculation. This topic research is helpful to improve the level of peanut shelling machine technology, reduce production cost of the machine, but also for the further promotion of the machine increased a little help.

\section{ACKNOWLEDGMENT}

I would like to express my gratitude to all those who helped me to write this thesis, especially my tutor, Professor Yongchang $\mathrm{Yu}$.thank him for his encourage and guidance. Also thanks to the support of agricultural machinery enterprises in Henan.

\section{REFERENCES}

[1] Li Jiandong, "The Experimental Study of Peanut Hulling Device," Qingdao: Qingdao Agriculture University, 2007, pp.3-5.

[2] Bao Xiaohui, "Study on Peanut Shelling Force Performance and Doubleroller Shell Principle," Shenyang: Shenyang Agriculture University, 2007.

[3] Wang Yanyao, Zhang Yan, Shang Shuqi, Zhang Xizhai , "Test Study on Performance of Peanuts Shelling by Gas Burst," Transactions of the Chinese Society Agriculture Engineering, March 1998, pp.222-227.

[4] Gao Lianxing, Du Xin, Zhang Wen, Liu Mingguo, "Double-roller Peanut Sheller with Pneumatic Circulating," Transactions of the Chinese Society for Agricultural Machinery, October 2011, pp.68-72.

[5] Li Xiaoxia, Guo Ming, "Acluality of the Decladding Method and Sheller of Shell Fruit," Academic Periodical of Farm Products Processing, April 2007, pp.83-86.

[6] Na Xuejiao,Liu Mingguo, Zhang Wen, Li Fei, Du Xin, Gao Lianxing, "Damage Characteristics and Regularity of Peanut Kernels," Transactions of the Chinese Society of Agricultural Engineering, May 2010.

[7] Zhou Ruibao, "Peanut Production, Processing Current Situation and Development Proposal in China," China Grease, 2005, PP.5 - 9.

[8] Wang Xinzhong, Wang Min., "Experiment on Mechanical Properties of the Seed Nucleus Og Ginkgo Biloba," Transactions of the Chinese Society for Agricultural Machinery, 2008, 39(8), PP. 84-88.

[9] Xu Lizhang, Li Yaoming, Wang Xianren, "Research development of grain damage during threshing," Transactions of the CSAE, 2009, 25(1), PP. 303-307. 